\title{
Evaluation of Groundwater Storage Variations in Northern China Using GRACE Data
}

\author{
Wenjie Yin, ${ }^{1,2}$ Litang $\mathrm{Hu},{ }^{1,2}$ and Jiu Jimmy Jiao ${ }^{3}$ \\ ${ }^{1}$ College of Water Sciences, Beijing Normal University, Beijing 100875, China \\ ${ }^{2}$ Engineering Research Center of Groundwater Pollution Control and Remediation of Ministry of Education, Beijing Normal University, \\ Beijing 100875, China \\ ${ }^{3}$ Department of Earth Sciences and Shenzhen Research Institute (SRI), The University of Hong Kong, Pokfulam, Hong Kong
}

Correspondence should be addressed to Litang Hu; litanghu@bnu.edu.cn

Received 6 April 2017; Revised 21 October 2017; Accepted 8 November 2017; Published 29 November 2017

Academic Editor: Stefano Lo Russo

Copyright (C) 2017 Wenjie Yin et al. This is an open access article distributed under the Creative Commons Attribution License, which permits unrestricted use, distribution, and reproduction in any medium, provided the original work is properly cited.

\begin{abstract}
Dynamic change of groundwater storage is one of the most important topics in the sustainable management of groundwater resources. Groundwater storage variations are firstly isolated from the terrestrial water storage change using the Global Land Data Assimilation System (GLDAS). Two datasets are used: (1) annual groundwater resources and (2) groundwater storage changes estimated from point-based groundwater level data in observation wells. Results show that the match between the GRACE-derived groundwater storage variations and annual water resources variation is not good in six river basins of Northern China. However, it is relatively good between yearly GRACE-derived groundwater storage data and groundwater storage change dataset in Huang-HuaiHai Plain and the Song-Liao Plain. The mean annual depletion rate of groundwater storage in the Northern China was approximately 1.70 billion $\mathrm{m}^{3} \mathrm{yr}^{-1}$ from 2003 to 2012. In terms of provinces, the yearly depletion rate is higher in Jing-Jin-Ji (Beijing, Tianjin, and Hebei province) and lowest in Henan province from 2003 to 2012, with the rate of 0.70 and $0.21 \mathrm{~cm} \mathrm{yr}^{-1}$ Equivalent Water Height (EWH), respectively. Different land surface models suggest that the patterns from different models almost remain the same, and soil moisture variations are generally bigger than snow water equivalent variations.
\end{abstract}

\section{Introduction}

As the world's largest distributed store of freshwater [1], groundwater supplies approximately half of the total global domestic water demand and is a major supplier of industrial and agricultural demands [2]. However, in many regions of the world, groundwater resources are under intense stress due to salinization, contamination, and rapid groundwater depletion $[3,4]$. Especially in some coastal cities, the situation is getting even worse. In China, close to $50 \%$ of the population lives in the coastal provinces and major cities [5]. Statistics show that Tianjin, Liaoning, Shandong, and Hebei, the four coastal cities in Northern China, had 15.5, 43.8, 98.5, and 74.3 million inhabitants, respectively, in 2016 [6]. Rapid urbanization and increasing population are putting more pressure on groundwater resources. In addition, overexploitation of groundwater resources will lead to more serious consequences compared with inland cities, such as saltwater instruction and coastal erosion. Therefore, effective monitoring of groundwater storage (GWS) variations is important for groundwater management. To monitor changes in the availability of groundwater, hydrological scientists mainly rely on observation wells. However, in arid regions or mountainous areas, it is difficult to obtain the regional GWS variations from wells because the observation wells are generally limited [7]. The Gravity Recovery and Climate Experiment (GRACE) satellite mission provides approximately monthly changes in terrestrial water storage (TWS) on the basis of measurements of the Earth's gravity field [8-10]. Nonhydrological gravitational contributions are removed from GRACE level-2 data based on numerical models of the processes, including atmospheric and ocean circulation and solid Earth tides, to present TWS variations [11]. Therefore, temporal variation in the gravity field is mainly due to terrestrial water storage change (TWSC), which is a vertically integrated measurement of groundwater, soil moisture, snow, ice, and surface water [12]. 


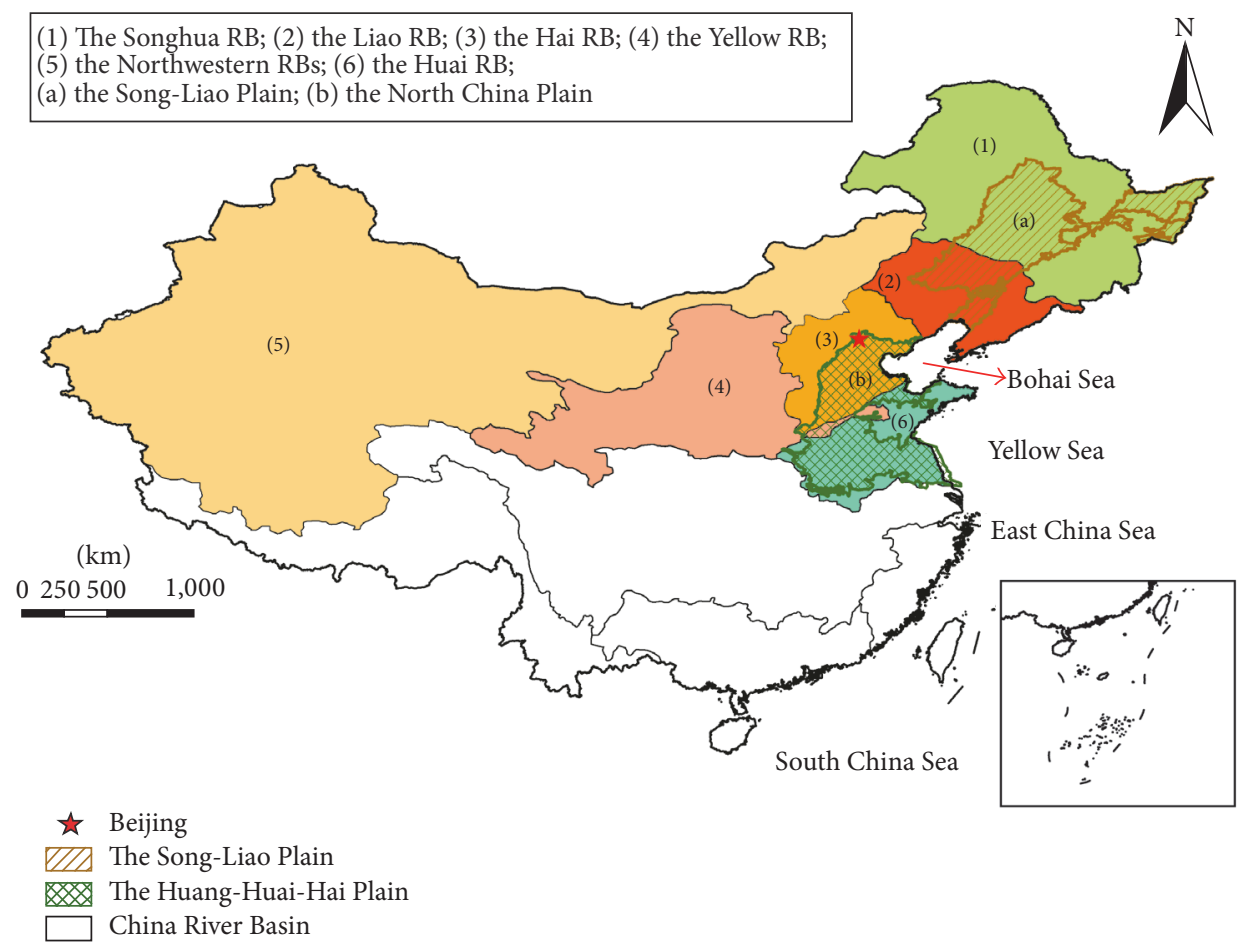

Figure 1: Schematic figure of ten river basins and two north plains in China.

GWS variations have been estimated in many parts of the world using the GRACE satellite data. One of the most promising applications of GRACE is to monitor the variations of land water or terrestrial water storage, in particular relatively large scale variations [13]. Rodell and Famiglietti [14] showed that it was feasible to use GRACE to sense groundwater changes in the High Plains aquifer of the central USA. Yeh et al. [15] found that groundwater estimates from GRACE agreed reasonably well with in situ observations in Illinois, USA. However, they noted that the agreement between the two results varied substantially from month to month. In general, the seasonal cycles between the estimated and measured groundwater changes agreed well with each other (the correlative coefficient is 0.83 with 36 observations). Leblanc et al. [16] performed a study of the multiyear drought in the Murray-Darling Basin, documenting the propagation of water deficits through the hydrological cycle. They found a high correlation between the observed groundwater variations from boreholes and the GRACE TWS estimates. Famiglietti et al. [17] studied the GRACE data in the Central Valley of California and concluded that groundwater was depleted at an annual rate of $20.4 \pm 3.9 \mathrm{~mm}$ Equivalent Water Height (EWH) in the valley, which was approximately two-thirds of the total water loss in the river basins. More recently, Sun et al. [18] formulated a means of estimating aquifer storage parameters from remotely sensed observations and modelled Soil Moisture Storage (SMS). They found that their estimated aquifer storage parameters were consistent with previous results derived from in situ observations and concluded that GRACE data can be used to derive spatially variable parameters for groundwater modelling.

Serious groundwater overdraft occurs in many arid and coastal regions of China. For example, in the Huang-HuaiHai Plain (HHHP), close to Yellow sea and the Bohai sea (Figure 1), groundwater overdraft has caused rapid water level decline and saltwater intrusion since the 1980s [19, 20]. The allowable deep groundwater resource is 2.06 billion $\mathrm{m}^{3} \mathrm{yr}^{-1}$. However, the yearly averaged groundwater utilization from 2003 to 2010 was more than 2.94 billion $\mathrm{m}^{3}$ [21]. Furthermore, the groundwater depletion rate estimated from monitoring well stations was between 2.0 and $2.8 \mathrm{~cm} \mathrm{yr}^{-1}$ from 2003 to 2010 [22]. To relieve the stress of groundwater overdraft, the Chinese government has invested over one billion yuan to implement the national groundwater monitoring project in recent years, which is jointly carried out by the Ministry of Land and Resources and the Ministry of Water Resources, China. Compared with the vast area of China, these existing observations wells are still limited. In addition, the Southto-North Water Transfer (SNWT) Project has been carried out to channel 44.8 billion $\mathrm{m}^{3}$ of fresh water annually from the Yangtze River in southern China to the more arid and industrialized north through three canal systems [23, 24]. The SNWT Project has Eastern, Central, and Western routes. The Central Route of the SNWT Project runs from Danjiangkou Reservoir in Hubei Province on the Han River, a tributary of the Yangtze River, to Beijing, Tianjin, and Hebei Province (denoted as Jing-Jin-Ji for short) (Figure 2), which will relieve the stress of the demand for water resources in these areas [25]. 


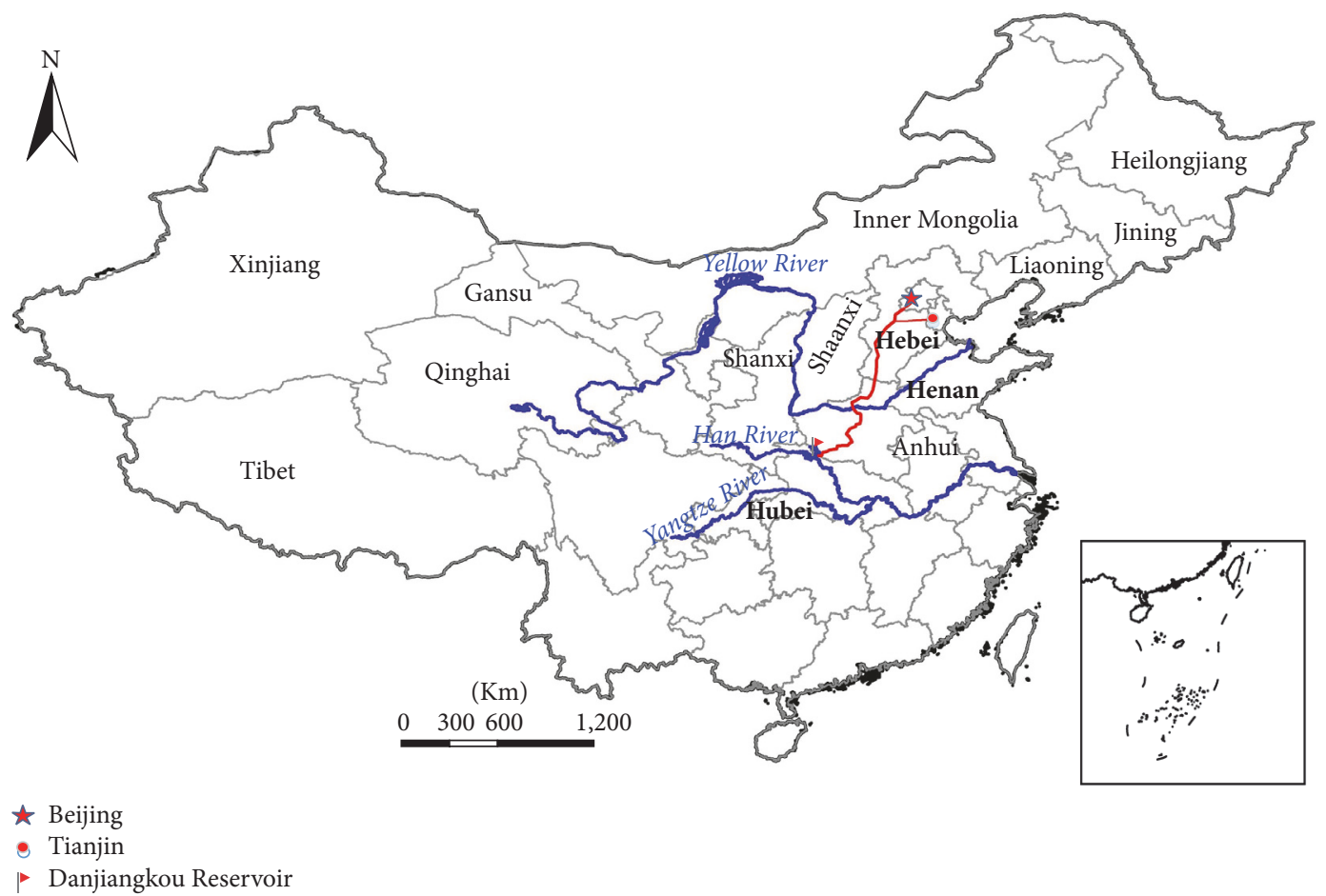

FIGURE 2: Schematic figure of the main provinces and the central route (red line) of the SNWT Project.

In this paper, soil moisture and snow water equivalent simulated from Global Land Data Assimilation System (GLDAS) are removed from the TWS changes observed by GRACE to estimate the groundwater variations and characterize their interannual variability. Two official datasets, Water Resources Bulletin of China and Monthly Reports of Groundwater Changes in the North of China by the Ministry of Water Resources (MWR), China, are used to evaluate the reliability of GRACE-derived GWS changes. Moreover, the rate of change of GWS is estimated for six basins and main provinces in Northern China, and these results will provide valuable scientific data for the rational use and management of groundwater resources in China. Finally, the measurement and leakage errors from GRACE data processing and the influences of different hydrological models on derived GWS variations will be discussed.

\section{Method}

The monthly GRACE-derived TWS data are freely downloadable. In areas where other water components are available, the groundwater storage variations can be calculated from the TWS variations [30]. TWS is a vertically integrated measurement of water storage changes that represents the sum of soil moisture, groundwater, surface water, snow, and ice. Rodell and Famiglietti [31] demonstrated that surface water storage variability in Illinois (USA) was, in nonflood years, at least an order of magnitude smaller than soil moisture and groundwater variability. The contribution of snow water to terrestrial water storage variability in the Mississippi River basin approaches $1 \mathrm{~cm}$ in some cases but is small compared to that of soil moisture. Therefore, the assumption is made here that regionally averaged surface water variability can be neglected in Northern China [11]. Groundwater, soil moisture, and snow water equivalents are therefore the only significant contributors to the variability in whole water storage observations. Thus, given GRACE-based estimates of changes in terrestrial water storage ( $\Delta \mathrm{TWS})$ and numerically modelled changes in soil moisture $(\Delta S M)$ and snow water equivalents $(\Delta \mathrm{SWE})$, changes in groundwater storage $(\Delta \mathrm{GW})$ are calculated as follows:

$$
\Delta \mathrm{GW}=\Delta \mathrm{TWS}-(\Delta \mathrm{SM}+\Delta \mathrm{SWE}),
$$

where $\Delta$ denotes monthly or yearly change. SM refers to volumetric soil moisture content, which is the volume of water stored within the soil column. In this study, GRACEderived groundwater storage changes will be compared with GWS changes estimated from the two official datasets.

2.1. TWS from GRACE. In this study, Release-05 of GRACE (GRACE-RL05) is used to derive the TWS from 2003 to 2012. GRACE-RL05 is more accurate than previously released products $[32,33]$. This is because the destriping procedure applied requires less spatial smoothing compared with the earlier versions of GRACE. For filling of missing months, linear interpolation was used according to Landerer and Swenson [28]. Specific gridded files include a monthly, $1^{\circ} \times 1^{\circ}$ CSR GRACE time-series dataset masked over the whole of China (land grid version; see https://grace.jpl.nasa.gov/data/) [34] wherein bias and leakage are compensated for by a scaling factor used to restore GRACE TWS signal amplitude for each grid. All anomalies in downloaded data are relative 
to average data over the period from January of 2004 to December of 2009.

The GRACE models do not include the first degree spherical terms, and Swenson et al. [35] added predictions to each monthly GRACE model. The $\mathrm{C}_{20}$ (degree 2 order 0 ) coefficients are replaced with the solutions from Satellite Laser Ranging, because the native GRACE-C20 values have larger uncertainties than the SLR values [36]. The degree-1 coefficients (Geocenter) are estimated using the method from Swenson, Chambers, and Whar. A decorrelation filter was used to suppress stripe noise, and smoothing with $300 \mathrm{~km}$ Gaussian filters [37] is applied to suppress noise at higher degrees and orders. A destriping filter has been applied to the data to minimize the effect of correlated errors whose telltale signals are N-S stripes in GRACE monthly maps. In addition, the hydrological signal extracted from GRACE can also be contaminated by glacial isostatic adjustment and crustal deformations caused by major earthquakes [38, 39]. A glacial isostatic adjustment (GIA) correction has been applied based on the model from Geruo et al. [40].

2.2. SM and SWE Data from GLDAS. Groundwater, soil moisture, and snow water are the significant contributors to the regional water storage observations. However, as reliable and spatially continuous measurements of soil moisture are not currently available, output from sophisticated land surface models driven by the Global Land Data Assimilation System (GLDAS) is used to provide SM and SWE estimates [41]. GLDAS is a data simulation system that incorporates in situ ground measurements and satellite-based observational data products using advanced land surface modelling and data assimilation techniques. GLDAS consists of four land surface models, namely, Noah [42], Community Land Model (CLM) [43], Mosaic [44], and Variable Infiltration Capacity (VIC) [45]. Tiwari et al. [46] compared the modelled groundwater anomalies from four hydrological models, including Noah, the Mosaic model, the Climate Prediction Center (CPC) model, and the Community Land Model (CLM), and concluded that the use of these different models would not notably affect the estimate of groundwater storage. For the purpose of simplicity, the GLDAS Noah model is applied to obtain the SM and SWE at a spatial resolution of $1^{\circ}$ and monthly temporal resolution. Time-series records of $\Delta S M$ of a spatial resolution of $1^{\circ} \times 1^{\circ}$ and the total depth of $\Delta \mathrm{SM}$ in Noah (4 layers) are $2.0 \mathrm{~m}$. Based on the studies by Dai et al. [43] and Shamsudduha et al. [47], the four land surface models (LSMs) do not include groundwater storage and soil moisture changes in deep unsaturated soil.

2.3. Datasets for Results Verification. According to the Ministry of Water Resources (MWR), China is divided into 10 river basins (Figure 1). The quantity of groundwater resources of the ten river basins is published in Water Resources Bulletin of China, which is issued annually by the MWR (http://www.mwr.gov.cn/zwzc/hygb/szygb/) and called WR datasets for short. The quantity of groundwater resources in each river basin is approximately the sum of groundwater resources in administrative regions, which is evaluated based on natural groundwater recharge by water managers in each province. The WR datasets cover the period from 1997 to 2014. However, the data of groundwater resources for each river basin (RB) is only recorded since 2005. As such, only data from 2005 to 2012 is available for this study.

GWS changes for the Song-Liao Plain and the HuangHuai-Hai Plain can be collected from the reports of monthly groundwater observations issued by the MWR (http://www .mwr.gov.cn/zwzc/hygb/dxsdtyb/), which is called GWS datasets for short. GWS changes are the products of the changes in groundwater level in observation wells between the month of this year and the same month of last year, specific yield, and the calculation area, which is estimated by water managers in each province. The scope of this investigation mainly covers the Huang-Huai-Hai Plain (HHHP) and the Song-Liao Plain (SLP). Monthly reports of the changes in groundwater levels are published for the period of January of 2010 to December of 2014. This period covers 60 months, but three of the months (February, March, 2013; March, 2014) have no data. Groundwater storage changes in these three months are set to be zero.

\section{Results}

The study area consists of six river basins and two plains in Northern China, which are highlighted in different colors (Figure 1). The quantity of groundwater resources in the whole of Northern China can be considered to be approximately the sum of the resources in the river basins of Northern China. To compare the results from official statistical reports with GRACE-derived results, the WR and GWS datasets in the report need to be presented in the same way as the satellite data. That is to say, observed groundwater resources change is calculated by the quantity of groundwater resources for a given year minus the average groundwater resources from 2004 to 2009. Groundwater storage variations are expressed as Equivalent Water Height $(\mathrm{EWH})$ in $\mathrm{cm}$. Note that the MR datasets stand for the quantities of groundwater resources, and GRACE-derived results are groundwater storage anomalies. The quantities of groundwater resources mainly depend on the recharge of groundwater. However, the GRACE-derived GWS depends on the imbalance of recharge and discharges of groundwater.

\subsection{Comparison of GWS Changes from GRACE and the WR} Datasets. The water resources bulletin by MWR lists groundwater resources for six river basins (the Songhua $R B$, the Liao RB, the Hai RB, the Yellow RB, the Northwestern RBs, and the Huai RB) from 2005 to 2012. In the bulletin, the yearly groundwater resources of six river basins are evaluated from precipitation infiltration and recharge of surface water. GWS variations are influenced by both groundwater recharge and discharge. The average annual change in groundwater resources from 2005 to 2012 in the Northern China based on the official statistics is $0.02 \mathrm{~cm}$ EWH. The yearly changes of groundwater resources from WR datasets and GWS variations from 2005 to 2012 are shown in Figure 3. Note that the black line stands for the groundwater resources variations of the total six RBs, represented as Equivalent Water Height (EWH) (Figure 3). The average annual change in 


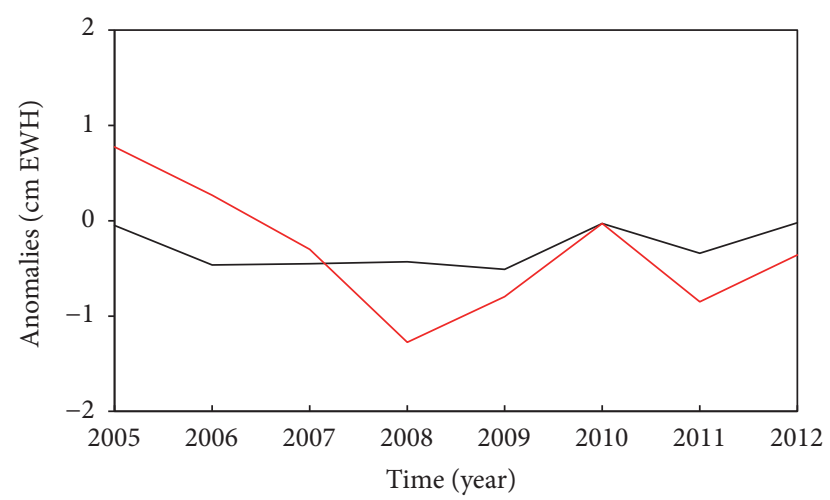

_ Groundwater resources variations from WR datasets — GRACE-derived GWS variations

Figure 3: Comparison of the annual changes in groundwater resources from the WR datasets and GRACE-derived GWS variations of the Northern China from 2005 to 2012.

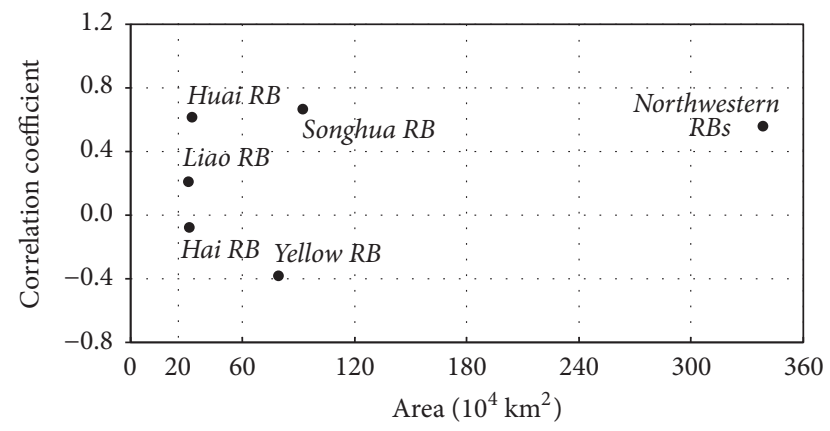

FIGURE 4: The relationship between correlation coefficient and area in six river basins of Northern China (see Figure 1 for the number of the river basins).

GRACE-derived GWS for this period is $-0.13 \mathrm{~cm}$ EWH. The standard deviation (SD) of annual average change in groundwater resources in Northern China based on the official statistics is $0.21 \mathrm{~cm} \mathrm{EWH}$, less than that of GRACEderived GWS of $0.60 \mathrm{~cm} \mathrm{EWH}$. Over the period of 2005 to 2012, the annual change in groundwater resources from official bulletins (the black line) is not well correlated with the GRACE-derived GWS annual change (the red line), as indicated by the linear correlation coefficient of 0.50 .

Figure 4 shows the area of the river basins and correlation coefficient between groundwater resource variations from the official reports and GRACE-derived GWS variations for the river basins in Northern China. It can be seen clearly that the correlation coefficient ranges from -0.38 to 0.67 . The correlation coefficients for the Songhua RB, the Huai RB, and the Northwestern RBs are all above 0.55 . However, the correlation for the certain parts of Northern China, such as the Yellow RB, is very poor. The correlation coefficient is -0.38 for the Yellow RB, -0.08 for the Hai RB, and 0.22 for the Liao RB. The poor correlation is probably caused by two main reasons: (1) the amount of groundwater extraction is the dominant component of the changes of groundwater storages; (2) GRACE-derived groundwater storage usually represents the change of mass in the entire depth of aquifer, which probably does not coincide with the depth of aquifer in the water resources bulletin.

3.2. Comparison of GWS Changes from GRACE with the GWS Datasets. Monthly reports of groundwater storage in Northern China by MWR summarize groundwater storage changes estimated from water level data from observation wells in the Song-Liao Plain and the Huang-Huai-Hai Plain (Figure 1). These data are called GWS datasets hereafter and are used for comparison with GRACE-derived GWS variations. Figure 5 shows the comparisons between the monthly measured and GRACE-derived GWS variations in the Huang-Huai-Hai Plain and the Song-Liao Plain. Figures 5(a) and 5(b) show that the agreement between the monthly measured and GRACEderived results varied substantially from month to month, but the overall pattern of monthly changes of both GRACEderived and measured GWS variations is very similar. However, the curves of GRACE-derived results show greater fluctuations over most months except in the Song-Liao Plain in 2011, probably because the measured GWS variations are estimated from point-based observation wells and errors incur from improper estimation method. The correlation coefficient between monthly measured and GRACE-derived results reaches 0.60 and 0.30, in the Huang-Huai-Hai Plain and the Song-Liao Plain, respectively. The poor match of monthly GWS changes in the Song-Liao Plain is mainly caused by the poor observation data in 2011 and 2014, and the measured range is concentrated in the plain area of these two plains. Besides, groundwater storage change in the Song-Liao Plain is probably not the dominant component of TWS, and thus neglecting the changes of surface water in (1) would cause errors when separating GWS from TWS. The correlation coefficient will reach 0.57 in the Song-Liao Plain when excluding the data in 2011 and 2014.

The 12 months in a year are divided into 4 seasons in China: March to May, June to August, and September to November belong to spring, summer, and autumn, respectively, and winter contains the remaining 3 months. In terms of quarterly scales, the correlation coefficient between the GRACE-derived and measured groundwater storage variations ranges from 0.61 to 0.89 during the period from 2010 to 2015 in Huang-Huai-Hai Plain (shown in Figure 6(a)). Generally, the measured GWS variations are larger than the GRACE-derived values. In the Song-Liao Plain, the correlation between the two series also gets higher compared to the monthly scales. The coefficient varies from 0.66 to 0.93 , and the correlation reaches the largest in autumn. In addition, the fluctuation amplitude of the measured result is larger than that of GRACE-derived (Figure 6(b)).

Comparisons between yearly changes of GRACE-derived and measured GWS variations are shown in Figure 7. The correlation coefficient between the two yearly results is 0.60 and 0.71, in the Huang-Huai-Hai Plain and the SongLiao Plain, respectively. The GRACE-derived yearly average depletion rate of groundwater is $0.67 \mathrm{~cm} \mathrm{yr}^{-1} \mathrm{EWH}$ in the Huang-Huai-Hai Plain, which is reasonable when compared with the previous studies in the North China Plain (Table 1), where the North China Plain is a part of the 


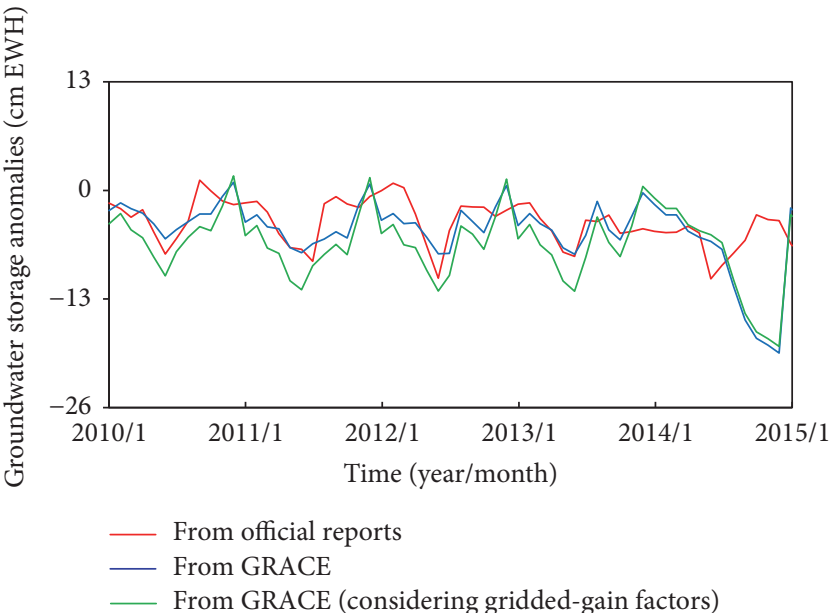

(a)

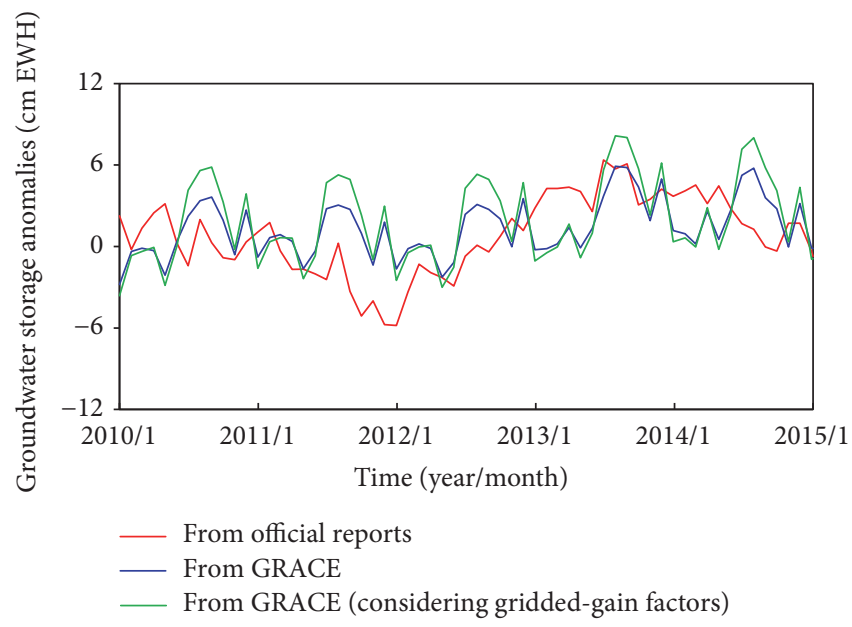

(b)

Figure 5: Comparison of the monthly measured and derived GWS variations in (a) the Huang-Huai-Hai Plain and (b) the Song-Liao Plain.

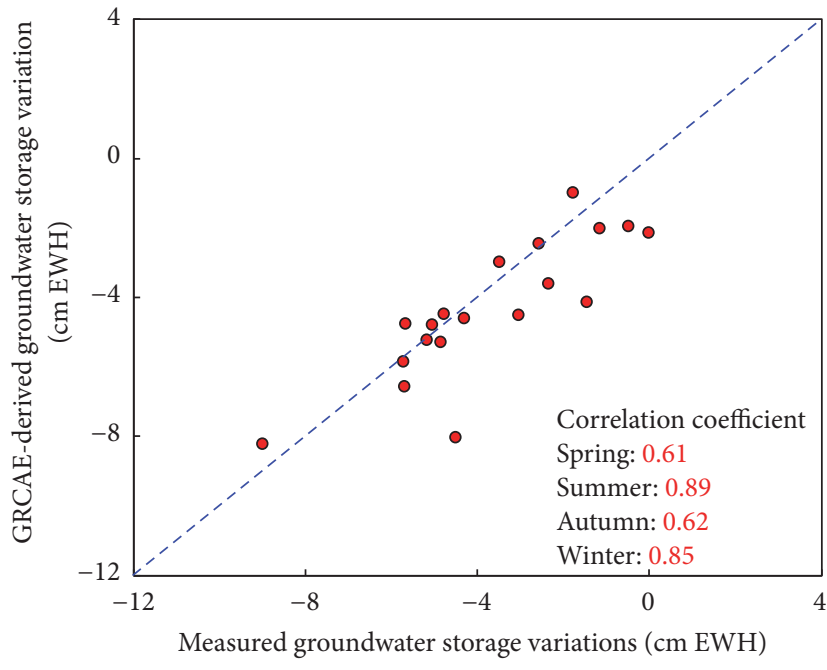

(a)

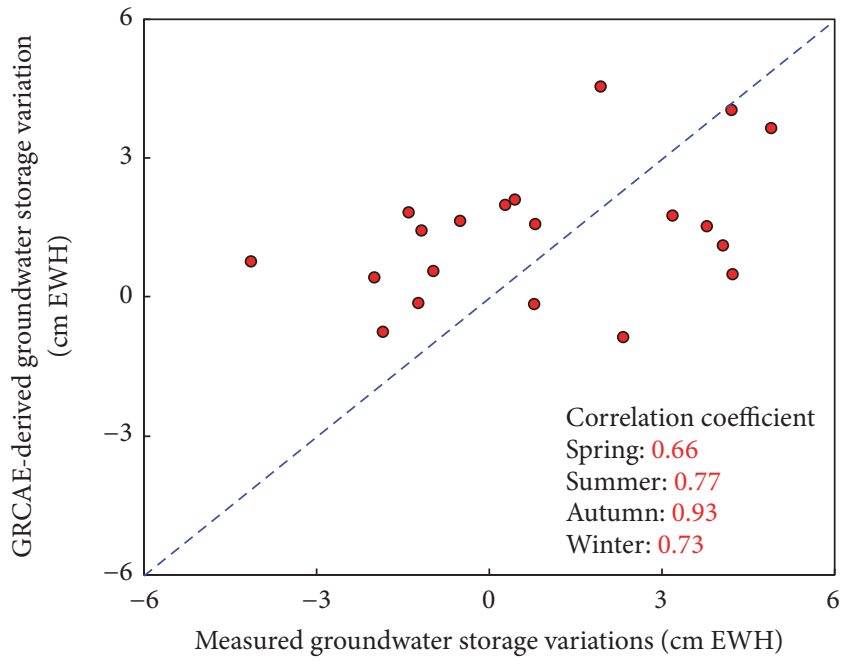

(b)

Figure 6: Comparison of the quarterly measured and derived GWS variations in (a) the Huang-Huai-Hai Plain and (b) the Song-Liao Plain.
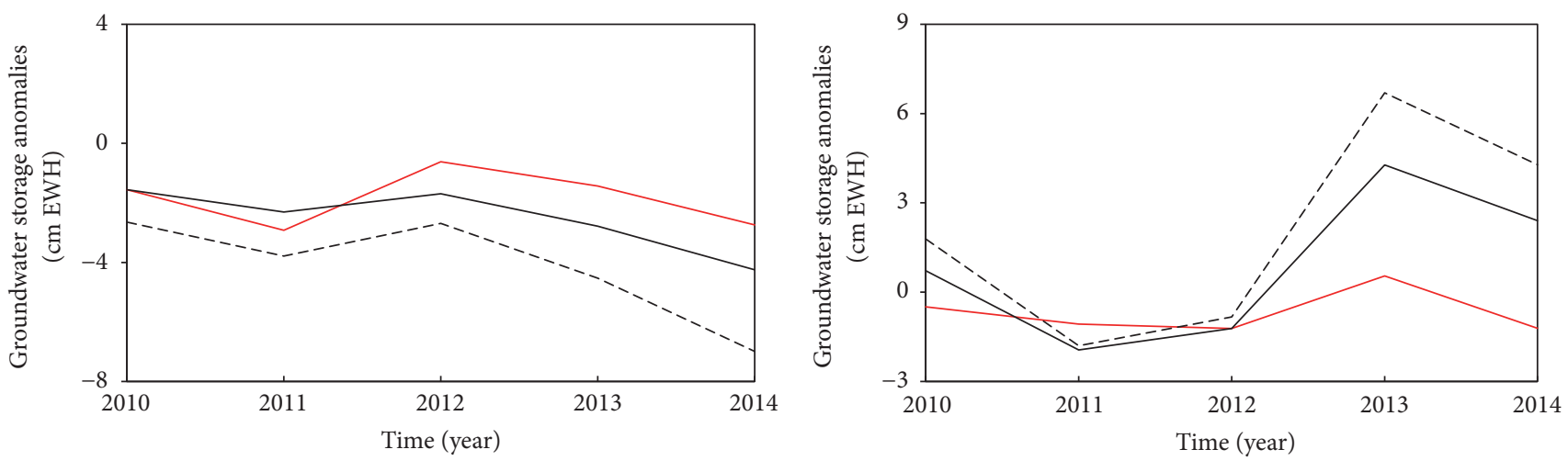

$\begin{array}{ll}\text { — } & \text { From official reports } \\ - & \text { From GRACE } \\ \text { - - } & \text { From GRACE (considering gridded-gain factors) }\end{array}$

(a)

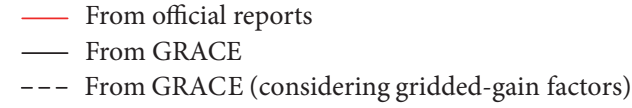

(b)

FIgure 7: Comparison of the annual measured and derived GWS variations in (a) the Huang-Huai-Hai Plain and (b) the Song-Liao Plain. 
TABLE 1: Results compared with previous studies in the North China Plain.

\begin{tabular}{lccc}
\hline Period & Study area $\left(\mathrm{km}^{2}\right)$ & Yearly depletion rate of groundwater $\left(\mathrm{cm} \mathrm{yr}^{-1}\right)$ & Authors \\
\hline $2003-2010$ & $\sim 370,000$ & $1.90 \sim 2.50$ & Feng et al. [26] \\
$2003-2011$ & $\sim 300,000$ & $0.84 \sim 1.40$ & Tang et al. [27] \\
$2005-2010$ & $\sim 140,000$ & $2.25 \sim 4.15$ & Huang et al. [22] \\
$2009-2014$ & $\sim 380,000$ & $0.67 \sim 1.15$ & Results in this paper \\
\hline
\end{tabular}

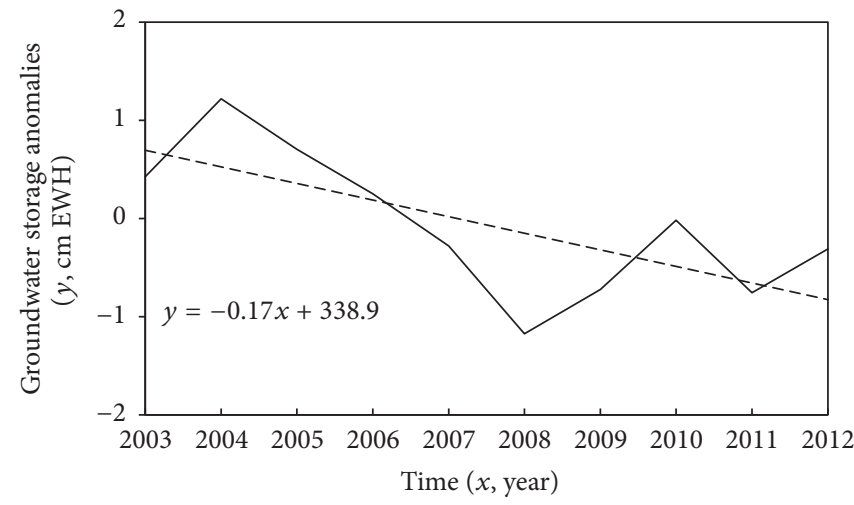

(a)

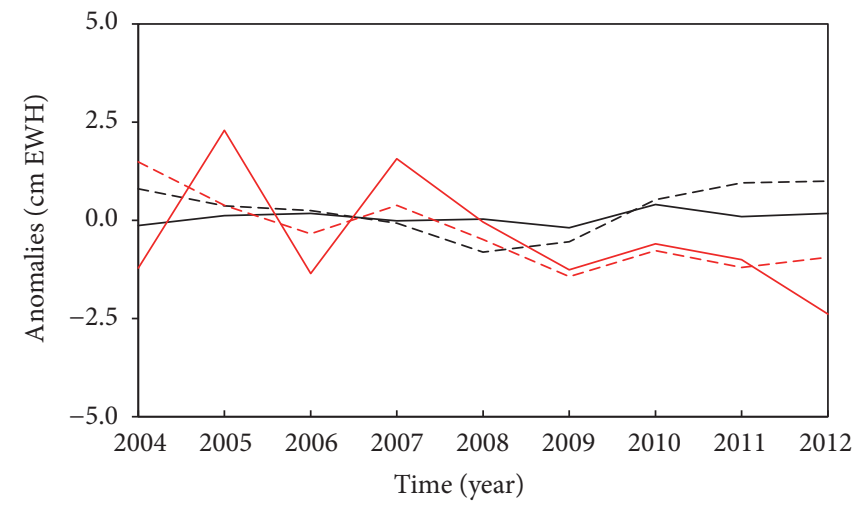

- The Northwestern RBs (WR datasets)

— The Huai RB (WR datasets)

--- The Northwestern RBs (GRACE-derived)

- - The Huai RB (GRACE-derived)

(b)

Figure 8: Variations of groundwater storage in Northern China and three river basins.

Huang-Huai-Hai Plain. The discrepancy in Figure 7 may be caused by the measurement error of GRACE-derived GWS and the inconsistent calculation area between GRACE data and data from official reports.

3.3. Depletion Rate of Groundwater in Northern China. Figure 8 shows the change of GRACE-derived GWS variations with time in the Northern China and two river basins (the Huai RB and the Northwestern RBs). The gridaveraged depletion rate of groundwater in Northern China is $0.17 \mathrm{~cm} \mathrm{yr}^{-1}$ EWH from 2003 to 2012, which means that groundwater storage in Northern China decreases at a rate of about 1.70 billion $\mathrm{m}^{3} \mathrm{yr}^{-1}$ (shown in Figure 8(a)). According to the official statistics of groundwater resources utilization [48], yearly increment of groundwater pumping is 2.50 2.60 billion $\mathrm{m}^{3}$ from 1970 to 1999 . The two sets of data record are basically consistent in order of magnitude, which suggests that GRACE-derived GWS variations are reasonable.

The solid and dashed lines in Figure 8(b) represent the measured and GRACE-derived GWS variations, respectively. The correlation coefficient in the Huai RB and the Northwestern RBs is 0.62 and 0.56 , respectively, which indicates that GRACE-derived results are reasonable (Figure 8(b)). The difference between the two results may be due to the fact that the area of the statistics is not exactly the same. Besides, the slope of trend line for the measured GWS data from 2004 to 2012 in the Huai RB and the Northwestern RBs is -0.28

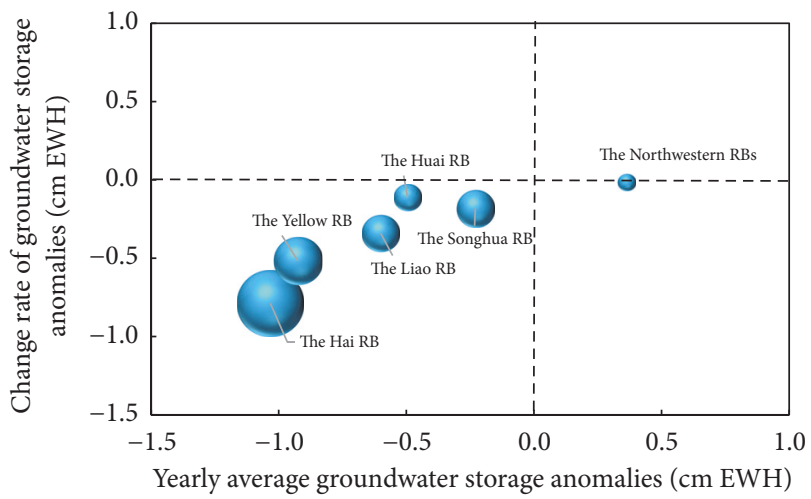

FIGURE 9: Changing trends of groundwater storage for the six river basins in Northern China from 2003 to 2012.

and $0.04 \mathrm{~cm} \mathrm{yr}^{-1}$, respectively. Results indicate that the GWS variations vary in different river basins.

Figure 9 shows the GWS variations in six river basins. The $x$ - and $y$-axes represent the yearly average GWS changes and the rate of change of GWS, respectively. The bubble size stands for the standard deviation of GRACE-derived GWS changes. Five of the river basins (the Songhua RB, the Hai RB, the Yellow RB, the Liao RB, and the Huai RB) are located in the bottom left corner, where groundwater storage shows a decreasing trend from 2003 to 2012 and the average 
TABLE 2: Change rates of yearly GWS variations in provinces from 2003 to 2012.

\begin{tabular}{lccccc}
\hline Name of province & Area $\left(\times 10^{4} \mathrm{~km}^{2}\right)$ & $\begin{array}{c}\text { Change rate } \\
\left(\mathrm{cm} \mathrm{yr}^{-1} \mathrm{EWH}\right)\end{array}$ & Name of province & Area $\left(\times 10^{4} \mathrm{~km}^{2}\right)$ & $\begin{array}{c}\text { Change rate } \\
\left(\mathrm{cm} \mathrm{yr}^{-1} \mathrm{EWH}^{2}\right.\end{array}$ \\
\hline Jing-Jin-Ji & 16.70 & -0.70 & Shandong & 10.67 & -0.49 \\
Shanxi & 15.22 & -1.01 & Henan & Tibet & 14.84 \\
Inner Mongolia & 80.19 & -0.29 & Shaanxi & 19.24 & -0.21 \\
Liaoning & 13.72 & -0.21 & Gansu & 32.83 & -0.32 \\
Jilin & 16.49 & -0.46 & Qinghai & 60.03 & -0.39 \\
Heilongjiang & 44.37 & -0.12 & Xinjiang & 99.38 & 0.56 \\
Anhui & 12.77 & 0.28 & & -0.09 \\
\hline
\end{tabular}

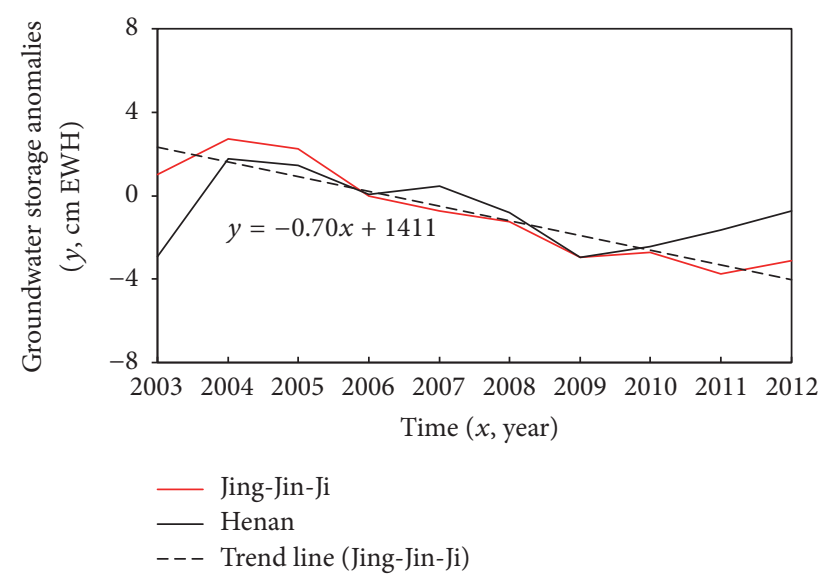

FIGURE 10: Change rate of groundwater storage in Jing-Jin-Ji region and Henan province involved in the SNWT Project.

annual GWS change is negative, suggesting that groundwater overdraft is serious and better groundwater management is required. A large bubble size suggests that GWS changes are highly variable from year to year in the period from 2003 to 2012. As far as the standard deviation of GWS change is concerned, the Hai RB has the largest bubble size with a SD of $2.58 \mathrm{EWH}$.

3.4. Depletion Rate of Groundwater in Some Provinces. The Central Route of the SNWT Project (Figure 2), which runs across Hubei, Henan, and Hebei provinces from the south to the north of China, was constructed in 2014. In this study, regional GWS changes in the Jing-Jin-Ji region and Henan province are estimated using GRACE data from 2003 to 2012 (Figure 10). Jing-Jin-Ji region has the yearly depletion rate of groundwater storage with $0.70 \mathrm{~cm} \mathrm{yr}^{-1} \mathrm{EWH}$ (Table 2). Henan province also shows a yearly depletion rate of groundwater at $0.21 \mathrm{~cm} \mathrm{yr}^{-1} \mathrm{EWH}$. The trend in GWS change also implies that the implementation of the SNWT Project will slow the depletion of stored groundwater in Henan province and Jing-Jin-Ji region.

It is noted that GRACE data processing may not be a critical issue over large basins (e.g., area $\geq 10^{6} \mathrm{~km}^{2}$ ) because bias and leakage offset each other but may be problematic for applying GRACE data to small basins less than the GRACE footprint [49]. The GRACE footprint is estimated to be $\sim 200,000 \mathrm{~km}^{2}$ based on the inherent resolution as a result of the satellite evaluation $\left(\sim 450 \times 450 \mathrm{~km}=\sim 200,000 \mathrm{~km}^{2}\right)$ [50]. In fact, recent researches confirm that a great progress has been made in the spatial resolution with the improvement of processing technology and algorithm since 2010, and working on areas of minimum $300 \times 300 \mathrm{~km}$ seems reasonable. Therefore, we select the provinces with larger areas $\left(>90,000 \mathrm{~km}^{2}\right)$ to analyze the changing rates of GWS in Northern China (Table 2). It can be found that all these coastal provinces (Liaoning, Shandong, and Jing-Jin-Ji) have groundwater depletion at various rates in Northern China. Shanxi province has the highest depletion rate of groundwater storage $\left(1.01 \mathrm{~cm} \mathrm{yr}^{-1} \mathrm{EWH}\right)$. The provinces of Anhui and Qinghai experience increases in groundwater storage from 2003 to 2012. Qinghai province has the largest increase rate of groundwater storage $\left(0.56 \mathrm{~cm} \mathrm{yr}^{-1} \mathrm{EWH}\right)$.

\section{Discussions}

4.1. Gridded Uncertainty Estimates. Errors in the restored TWS anomalies include GRACE measurement error in monthly gravity filed solutions [51] and leakage error (leakage error here includes both bias and leakage errors defined in our study). The leakage error results from the deviation from the filtered TWS anomalies applied with the same scaling factors and original TWS anomalies from a land surface model. Both measurements error and leakage error for each grid cell are available at the JPL website (https://grace.jpl .nasa.gov/data/get-data/monthly-mass-grids-land/). Measurement and leakage errors are assumed to be constant over time for each grid in the gridded products and are assumed in quadrature to estimate the total error for each grid.

At the basin scale, measurement or leakage errors of a study basin are spatially correlated and should be lower than those calculated by simply averaging errors of grid cells with a basin. Therefore, to obtain a more realistic error or leakage error at grid cells for the basin, an approach accommodating spatial correlation of errors was used as in the following formulas [28].

$$
\begin{aligned}
& \sigma_{\mathrm{mb}(\mathrm{lb})}=\frac{\sqrt{\mathrm{var}}}{N} \\
& \operatorname{var}=\sum_{i=1}^{N} \sum_{j=1}^{N} w_{i} w_{j} \operatorname{cov}\left(w_{i}, w_{j}\right)
\end{aligned}
$$


TABLE 3: TWS errors estimation in river basins and representative provinces from 2003 to 2012.

\begin{tabular}{|c|c|c|c|c|c|c|}
\hline & Locations & $\begin{array}{c}\text { Area } \\
\left(\times 10^{4} \mathrm{~km}^{2}\right)\end{array}$ & $\begin{array}{c}\text { Yearly averaged } \\
\text { GWS variation } \\
(\mathrm{cm} \mathrm{EWH})\end{array}$ & $\begin{array}{c}\text { Yearly change rate of } \\
\text { GWS variation } \\
\left(\mathrm{cm} \mathrm{yr}^{-1}\right)\end{array}$ & $\begin{array}{l}\text { Measurement } \\
\text { errors }^{*}(\mathrm{~cm})\end{array}$ & $\begin{array}{l}\text { Leakage errors }{ }^{*} \\
(\mathrm{~cm})\end{array}$ \\
\hline \multirow{2}{*}{ Province } & Jing-Jin-Ji & 21.83 & -0.85 & -0.70 & 1.22 & 2.32 \\
\hline & Henan & 16.70 & -0.77 & -0.21 & 1.82 & 2.42 \\
\hline \multirow{6}{*}{ River basin } & The Songhua RB & 92.49 & -0.23 & -0.18 & 1.02 & 0.92 \\
\hline & The Liao RB & 31.38 & -0.6 & -0.34 & 1.11 & 1.10 \\
\hline & $\begin{array}{c}\text { The Northwestern } \\
\text { RBs }\end{array}$ & 338.71 & 0.36 & -0.02 & 0.55 & 0.39 \\
\hline & The Hai RB & 31.82 & -1.03 & -0.79 & 1.33 & 1.57 \\
\hline & The Yellow RB & 79.21 & -0.93 & -0.52 & 0.89 & 0.90 \\
\hline & The Huai RB & 33.17 & -0.49 & -0.11 & 1.77 & 1.63 \\
\hline
\end{tabular}

* The measured errors and leakage errors are calculated based on Landerer and Swenson [28] and Long et al. [29].

$$
\begin{aligned}
& \operatorname{cov}\left(x_{i}, x_{j}\right)=\sigma_{i} \sigma_{j} \exp \left(\frac{-d_{i, j}^{2}}{2 d_{0}^{2}}\right) \\
& d_{i, j}=a \frac{\pi}{180} \\
& \cdot \sqrt{[\operatorname{long}(i)-\operatorname{lon}(j) \cos (\operatorname{lat}(i))]^{2}+[\operatorname{lat}(i)-\operatorname{lat}(j)]^{2}},
\end{aligned}
$$

where $\sigma_{\mathrm{mb}}$ is the measurement error of a basin; $\sigma_{\mathrm{lb}}$ is the leakage error of a basin; $N$ is the number of grid cells in a basin; subscripts $i$ and $j$ represent two different grid cells in a basin; var is the measurement or leakage error variance of mean TWS anomalies of a basin; $w$ is the area weight at each grid cell in the basin and simplified to $1 / N$ under the assumption of equal contribution from each grid cell to the basin average TWS anomalies; cov is the covariance between two grid cells; $\sigma$ is the standard deviation of measurement or leakage error of a grid cell; $d_{i, j}$ is the distance between two grid cells; $d_{0}$ is a decorrelation-length scale, that is, $300 \mathrm{~km}$ for measurement error and $100 \mathrm{~km}$ for leakage error; $a$ is Earth's radius $(6371 \mathrm{~km})$; long and lat denote longitude and latitude of a grid cell.

Following the error analysis calculated based on formula (2), the GRACE TWS errors for river basins and provinces are shown in Table 3. It can be found that the errors in each river basin and province are generally about $1 \mathrm{~cm} \mathrm{EWH.}$ Usually, the measurement and leakage errors in Jing-Jin-Ji and Henan provinces are larger than those in river basins, which indicates TWS errors decrease with the increase of the study area. The yearly average GWS variation decreases in almost all the six river basins except the Northwestern RBs, and the Hai RB has the largest GWS variations $(-1.03 \mathrm{~cm}$ EWH). The change rates of GWS in six river basins and two provinces are negative, and the largest depletion rate appears in the Huai RB, with the value of $0.79 \mathrm{~cm} \mathrm{yr}^{-1}$. Both measurement and leakage errors are largest in Huai RB; the reason may be related to the longer coastline and the stronger human activities.
TABLE 4: Correlation coefficient about SM among different LSMs in the Huang-Huai-Hai Plain.

\begin{tabular}{lcccc}
\hline LSMs & Mosaic & CLM & Noah & VIC \\
\hline Mosaic & 1 & & & \\
CLM & 0.74 & 1 & & \\
Noah & 0.76 & 0.91 & 1 & \\
VIC & 0.85 & 0.72 & 0.70 & 1 \\
\hline
\end{tabular}

4.2. Error Analysis from Land Surface Models. The overall modelling strategy of GLDAS is to drive multiple, offline land surface models (LSMs), integrate a huge quantity of observation-based data, and generate global datasets with high resolution, enabled by the Land Information System. Four LSMs (Mosaic, Noah, CLM, and VIC) are used to analyze the influences of land surface models on soil moisture and snow water melt changes. The four LSMs in GLDAS define different numbers of soil layers and also different corresponding soil depth. The Noah model has four soil layers: $0-10 \mathrm{~cm}, 10-40 \mathrm{~cm}$, $40-100 \mathrm{~cm}$, and $100-200 \mathrm{~cm}$. The Mosaic model defines three soil layers: $0-2 \mathrm{~cm}, 2-150 \mathrm{~cm}$, and $150-350 \mathrm{~cm}$. Three soil layers are used in the VIC model, that is, $0-10 \mathrm{~cm}, 10-160 \mathrm{~cm}$, and $160-190 \mathrm{~cm}$. The CLM model defines the most soil layers: 0-1.8 cm, $1.8-4.5 \mathrm{~cm}, 4.5-9.1 \mathrm{~cm}, 9.1-16.6 \mathrm{~cm}, 16.6-28.9 \mathrm{~cm}$, $28.9-49.3 \mathrm{~cm}, 49.3-82.9 \mathrm{~cm}, 82.9-138.3 \mathrm{~cm}, 138.3-229.6 \mathrm{~cm}$, and $229.6-343.3 \mathrm{~cm} \mathrm{[52].}$

Comparison of the temporal evolution of the simulation results from four LSMs is made in Figures 11 and 12. It can be found that the surface soil moisture displays large seasonal variation, and the changes of soil moisture variations are basically consistent in the four LSMs (Figure 11). However, the amplitude of variation is somewhat different. The Mosaic model displays the largest variability, while the CLM model exhibits lowest variability among the four models. The discrepancies in GLDAS results are due to different model structures among four LSMs. In terms of periodic vibration, all the four LSMs can produce the similar results, and the correlation coefficients are shown in Table 4. It should be noted that the Noah model is in the best correlation with the 


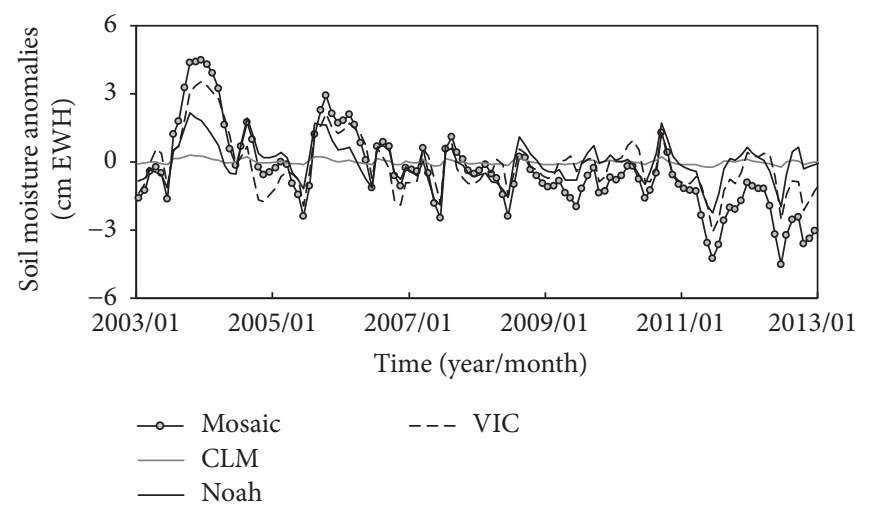

(a)

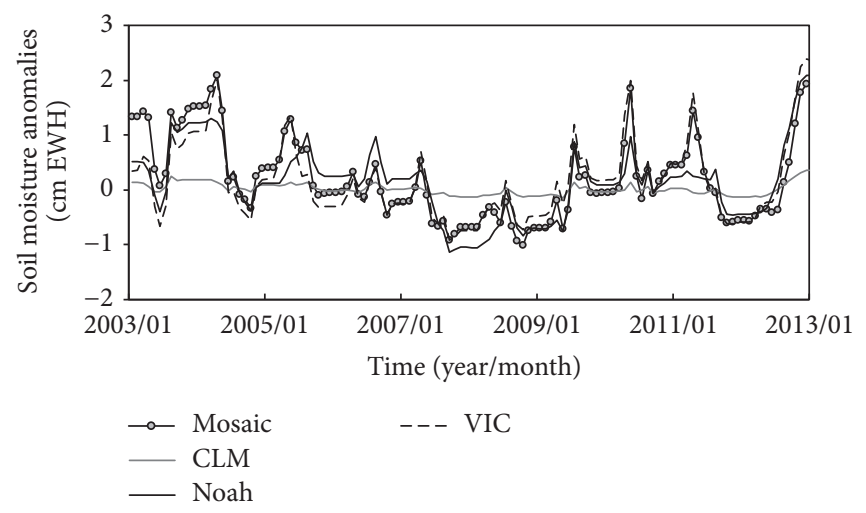

(b)

FIgure 11: Monthly temporal variations of soil moisture of four LSMs in GLDAS in (a) the Huang-Huai-Hai Plain and (b) the Song-Liao Plain.

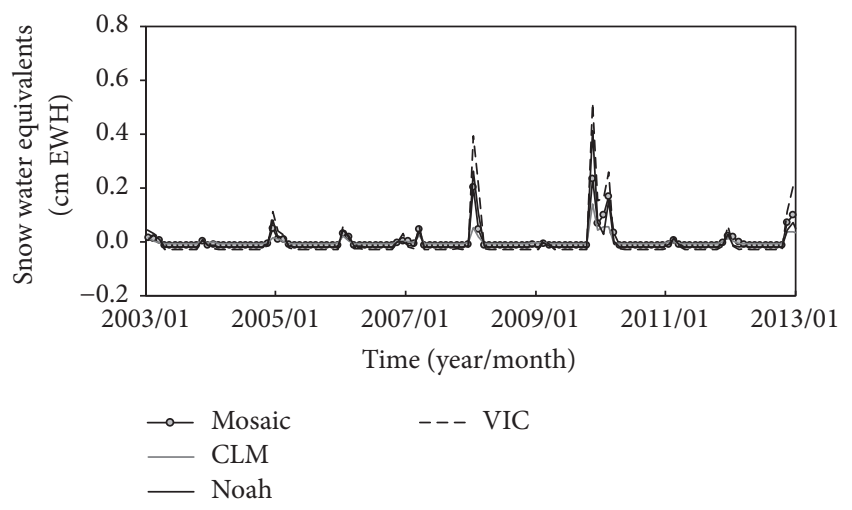

(a)

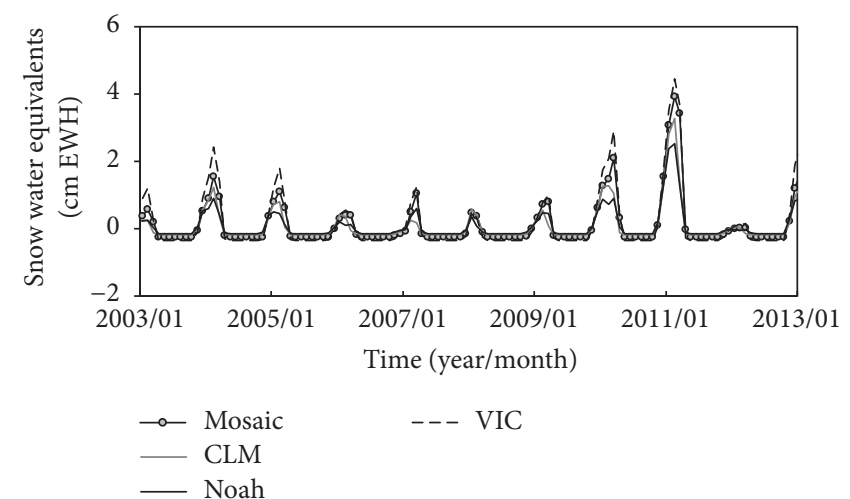

(b)

FIGURE 12: Monthly temporal variations of snow water equivalents of four LSMs in GLDAS in (a) the Huang-Huai-Hai Plain and (b) the Song-Liao Plain.

CLM model with the correlation coefficient of 0.91 , while the VIC model shows the worst correlation with the Noah model with the correlation coefficient of 0.70 . It is observed from Figure 12 that the amplitude of snow water equivalent is much smaller than that of soil moisture. The amplitude is almost in the vicinity of $0 \mathrm{~cm}$, apart from December and January. Though the four LSMs have different variation amplitude, the temporal variations of SWE are basically consistent from 2003 to 2012 . The VIC model displays the largest variability compared with other models both in Huang-Huai-Hai Plain (Figure 12(a)) and the Song-Liao Plain (Figure 12(b)).

Errors of snow water equivalent and soil moisture in GLDAS models (VIC, Noah, Mosaic, and CLM) are calculated from the method proposed by Kato et al. [53], which are the standard deviations of the trends. The errors in SM and SWE estimation are shown in Table 5, which shows monthly errors from LSMs [54]. It can be seen that the errors in SM estimation are basically larger than that in SWE estimation, ranging from 0.94 to $5.18 \mathrm{~mm}$. The larger LSMs errors appear in the Huang-Huai-Hai Plain among the two plains, with the value of $4.21 \mathrm{~mm}$. In addition, the Huai RB has the largest LSMs errors among the five river basins, due to its larger SM errors.
4.3. Scale Factor Analysis. GRACE spherical harmonic (SH) coefficients are destriped, truncated at the maximum degree and order of 60 , and filtered using a $300 \mathrm{~km}$ Gaussian filter. Truncation and filtering tend to attenuate some of the signal [55]. The GRACE signal is consequently restored by multiplying the filtered data with the scale factor. As described in previous studies [17, 29, 56], the gridded-gain factors are provided from the filtered gridded GRACE data can be downloaded from the website (https://grace.jpl.nasa .gov/data/get-data/monthly-mass-grids-land/). Here, the gridded-gain factors are used to analyze the influences of scale factor on GRACE-derived GWS changes. It is noted that the scaling factor $>1.0$ represents the process of destriping, truncation, and filtering result in signal loss over most of the land surface. Therefore, the filtered GRACE signal needs to be compensated by multiplying a scaling factor that is generally over 1.0.

Considering the scale factor, comparison of the measured and GRACE-derived GWS anomalies for monthly and yearly scales is shown in Figures 5 and 6. Amplitudes of GRACEderived GWS variations are generally increased when considering gridded-gain factors. The correlation coefficient between the yearly observed and GRACE-derived GWS 
TABLE 5: Errors estimation from four land surface models in different places of Northern China.

\begin{tabular}{|c|c|c|c|c|c|}
\hline & \multirow{2}{*}{ Locations } & \multirow{2}{*}{$\begin{array}{c}\text { Area } \\
\left(\times 10^{4} \mathrm{~km}^{2}\right)\end{array}$} & \multicolumn{3}{|c|}{ Error $(\mathrm{mm})$} \\
\hline & & & SWE estimation & SM estimation & Total \\
\hline \multirow{2}{*}{ Plain } & The Huang-Huai-Hai Plain & 56.01 & 0.23 & 4.21 & 4.21 \\
\hline & The Song-Liao Plain & 71.64 & 1.88 & 1.91 & 2.68 \\
\hline \multirow{6}{*}{ River basin } & The Songhua RB & 92.49 & 0.59 & 2.07 & 2.15 \\
\hline & The Liao RB & 31.38 & 0.28 & 2.20 & 2.22 \\
\hline & The Northwestern RBs & 338.71 & 0.69 & 0.58 & 0.90 \\
\hline & The Hai RB & 31.82 & 0.10 & 1.26 & 1.26 \\
\hline & The Yellow RB & 79.21 & 0.05 & 0.94 & 0.94 \\
\hline & The Huai RB & 33.17 & 0.04 & 5.18 & 5.18 \\
\hline
\end{tabular}

variations increases from 0.60 to 0.62 when considering scaling factors in the Huang-Huai-Hai Plain and from 0.71 to 0.72 in the Song-Liao Plain. The fitting of GRACE-derived GWS variations with the measured data is generally enhanced when considering scale factors.

\section{Summary}

Overabstraction of groundwater is an acute and growing challenge in China, especially the arid regions and coastal cities. It is difficult to observe its real-time changes due to groundwater stored underground. Traditional observation wells provide important groundwater data for the effective management of groundwater resources. However, such pointbased data usually represent the change of groundwater storage in localized areas. In most mountainous or remote regions, observation wells are sparse. The launch of the Gravity Recovery and Climate Experiment (GRACE) enables the detection of changes in TWS at large regional scales. In the present study, GRACE data are used to evaluate the changes in GWS in Northern China. Two official observational datasets from MWR in China are used to verify the accuracy of GRACE-derived GWS. In Northern China, GRACE-derived GWS variations show a low agreement with the changes in groundwater resources estimated from the WR dataset from 2005 to 2012, which may be caused by groundwater storage being significantly influenced by groundwater extraction. GRACE-derived GWS variations are compared with GWS dataset by MWR. Correlation coefficient between yearly measured GWS data and GRACE-derived GWS variations reaches 0.60 in the Huang-Huai-Hai Plain and 0.71 in the Song-Liao Plain from 2010 to 2014. However, the correlation coefficient between monthly changes of measured and GRACE-derived GWS variations is low and the agreement between the two results varied substantially from month to month, probably because the point-based measurement may under- or overestimate the change of GWS over the regional scale.

The change of GWS in six river basins and 14 provinces based on GRACE data demonstrates that the average annual depletion rate of groundwater is approximately $0.17 \mathrm{~cm} \mathrm{yr}^{-1}$ EWH in the Northern China over the period from 2003 to 2012. Almost all the five river basins and provinces, located in Northern China, show decreasing groundwater storage, suggesting that groundwater storage decreased in these river basins during those ten years. Jing-Jin-Ji region and Henan province experience a decreasing trend at the rate of -0.70 and $-0.21 \mathrm{~cm} \mathrm{yr}^{-1} \mathrm{EWH}$; it is therefore expected that the implementation of the Central Route of the SNWT Project will reduce groundwater storage overuse after displacing water use with surface water. In order to minimize the difference between GRACE-derived GWS anomalies and measured results, the gridded-gain factors are used and compared, which show that the correlation is somewhat enhanced when considering gridded-gain factors, while the effects are not obvious.

Due to the measurement and signal processing, it is inevitable to produce a series of errors, such as measurement error and leakage error. Results suggest that the errors in each river basin and provinces are generally about $1 \mathrm{~cm} \mathrm{EWH.} \mathrm{In}$ addition, errors decrease with the increase of the study area, and both measurement errors and leakage errors are largest in Huai RB. Since the different gravity field and hydrological models vary, large discrepancy may be found among different LSMs in many parts of China. Results in Northern China also found that the patterns of SM and SWE changes among four LSMs (VIC, Noah, Mosaic, and CLM) almost remain the same, and SM errors are overly much larger than SWE errors.

The variability of surface water storage is small in Northern China and usually neglected due to difference in spatial resolution and lack of detailed monitoring data, which will introduce a certain amount of error to the estimation of GWS variations. For example, in studies of the Amazon River basin, the variability in surface water storage accounts for approximately $5 \%$ of the variability in TWS [57]. The reliability of GRACE-derived GWS variations in some areas depends on the spatial accuracy of GRACE data and then needs to be further investigated.

\section{Disclosure}

An earlier version of this work was presented as poster " $43 \mathrm{rd}$ IAH Congress," 2016.

\section{Conflicts of Interest}

The authors declare no financial conflicts of interest. 


\section{Acknowledgments}

This work was supported by the National Natural Science Foundation of China (Grant no. 41572220) and the Beijing Natural Science Foundation (J150002).

\section{References}

[1] K. Kemper, "Groundwater-from development to management," Hydrogeology Journal, vol. 12, pp. 3-5, 2004.

[2] R. Xiao, X. He, Y. Zhang, V. G. Ferreira, and L. Chang, "Monitoring groundwater variations from satellite gravimetry and hydrological models: A comparison with in-situ measurements in the mid-atlantic region of the United States," Remote Sensing, vol. 7, no. 1, pp. 686-703, 2015.

[3] Y. Wada, L. P. H. Van Beek, C. M. Van Kempen, J. W. T. M. Reckman, S. Vasak, and M. F. P. Bierkens, "Global depletion of groundwater resources," Geophysical Research Letters, vol. 37, no. 20, Article ID L20402, 2010.

[4] E. Custodio, M. D. C. Cabrera, R. Poncela, L.-O. Puga, E. Skupien, and A. del Villar, "Groundwater intensive exploitation and mining in Gran Canaria and Tenerife, Canary Islands, Spain: Hydrogeological, environmental, economic and social aspects," Science of the Total Environment, vol. 557-558, pp. 425437, 2016.

[5] Q. He, M. D. Bertness, J. F. Bruno et al., "Economic development and coastal ecosystem change in China," Scientific Reports, vol. 4, article no. 5995, 2014.

[6] NBSC, Chinese Statistical Yearbook. National Bureau of Statistics of China (NBSC). China Statistics Press, Beijing, (2016).

[7] Y. Cao, Z. Nan, and G. Cheng, "GRACE gravity satellite observations of terrestrial water storage changes for drought characterization in the arid land of northwestern China," Remote Sensing, vol. 7, no. 1, pp. 1021-1047, 2015.

[8] J. J. Jiao, X. Zhang, and X. Wang, "Satellite-based estimates of groundwater depletion in the Badain Jaran Desert, China," Scientific Reports, vol. 5, article no. 8960, 2015.

[9] B. D. Tapley, S. Bettadpur, J. C. Ries, P. F. Thompson, and M. M. Watkins, "GRACE measurements of mass variability in the Earth system," Science, vol. 305, no. 5683, pp. 503-505, 2004.

[10] J. Wahr, S. Swenson, V. Zlotnicki, and I. Velicogna, "Timevariable gravity from GRACE: first results," Geophysical Research Letters, vol. 31, no. 11, 2004.

[11] M. Rodell, J. Chen, H. Kato, J. S. Famiglietti, J. Nigro, and C. R. Wilson, "Estimating groundwater storage changes in the Mississippi River basin (USA) using GRACE," Hydrogeology Journal, vol. 15, no. 1, pp. 159-166, 2007.

[12] G. Strassberg, B. R. Scanlon, and D. Chambers, "Evaluation of groundwater storage monitoring with the GRACE satellite: case study of the high plains aquifer, Central United States," Water Resources Research, vol. 45, no. 5, Article ID W054102009, 2009.

[13] D. Long, Y. Pan, J. Zhou et al., "Global analysis of spatiotemporal variability in merged total water storage changes using multiple GRACE products and global hydrological models," Remote Sensing of Environment, vol. 192, pp. 198-216, 2017.

[14] M. Rodell and J. S. Famiglietti, “The potential for satellite-based monitoring of groundwater storage changes using GRACE: The High Plains aquifer, Central US," Journal of Hydrology, vol. 263, no. 1-4, pp. 245-256, 2002.

[15] P. J.-F. Yeh, S. C. Swenson, J. S. Famiglietti, and M. Rodell, "Remote sensing of groundwater storage changes in Illinois using the Gravity Recovery and Climate Experiment (GRACE)," Water Resources Research, vol. 42, no. 12, Article ID W12203, 2006.

[16] M. J. Leblanc, P. Tregoning, G. Ramillien, S. O. Tweed, and A. Fakes, "Basin-scale, integrated observations of the early 21st century multiyear drought in Southeast Australia," Water Resources Research, vol. 45, no. 4, Article ID W04408, 2009.

[17] J. S. Famiglietti, M. Lo, S. L. Ho et al., "Satellites measure recent rates of groundwater depletion in California's Central Valley," Geophysical Research Letters, vol. 38, no. 3, Article ID L03403, 2011.

[18] A. Y. Sun, R. Green, M. Rodell, and S. Swenson, "Inferring aquifer storage parameters using satellite and in situ measurements: Estimation under uncertainty," Geophysical Research Letters, vol. 37, no. 10, Article ID L10401, 2010.

[19] H. Qin, G. Cao, M. Kristensen et al., "Integrated hydrological modeling of the North China Plain and implications for sustainable water managemen," Hydrology and Earth System Sciences, vol. 17, pp. 3759-3778, 2013.

[20] Y. Shu, K. G. Villholth, K. H. Jensen, S. Stisen, and Y. Lei, "Integrated hydrological modeling of the North China Plain: Options for sustainable groundwater use in the alluvial plain of Mt. Taihang," Journal of Hydrology, vol. 464-465, pp. 79-93, 2012.

[21] S. Jiansheng, W. Zhao, and Z. Zhaoji, "Assessment of overexploitation of deep groundwater in the North China Plain," Earth Science Frontiers, vol. 17, pp. 215-220, 2010.

[22] Z. Huang, Y. Pan, H. Gong et al., "Subregional-scale groundwater depletion detected by GRACE for both shallow and deep aquifers in North China Plain," Geophysical Research Letters, vol. 42, no. 6, pp. 1791-1799, 2015.

[23] X. Chan, X. Ping, T. Tao, and C. Li, "Influence of middle route of South-to-North Water Diversion Project on hydrological regime in middle and lower reaches of Hanjiang River," Journal of China Hydrology, vol. 1, p. 006, 2009.

[24] L. Yanjun, H. Peng, X. Weihua, and L. Bo, “The research of water environment cumulative impacts of delivery canal on East Route of South-to-North Water Transfer Project," Procedia Engineering, vol. 28, pp. 287-291, 2012.

[25] X. Wang, J. Zhu, F. Ma, C. Li, Y. Cai, and Z. Yang, "Bayesian network-based risk assessment for hazmat transportation on the Middle Route of the South-to-North Water Transfer Project in China," Stochastic Environmental Research and Risk Assessment, vol. 30, no. 3, pp. 841-857, 2016.

[26] W. Feng, M. Zhong, J.-M. Lemoine, R. Biancale, H.-T. Hsu, and J. Xia, "Evaluation of groundwater depletion in North China using the Gravity Recovery and Climate Experiment (GRACE) data and ground-based measurements," Water Resources Research, vol. 49, no. 4, pp. 2110-2118, 2013.

[27] Q. Tang, X. Zhang, and Y. Tang, "Anthropogenic impacts on mass change in North China," Geophysical Research Letters, vol. 40, no. 15, pp. 3924-3928, 2013.

[28] F. W. Landerer and S. C. Swenson, "Accuracy of scaled GRACE terrestrial water storage estimates," Water Resources Research, vol. 48, no. 4, 2012.

[29] D. Long, L. Longuevergne, and B. R. Scanlon, "Global analysis of approaches for deriving total water storage changes from GRACE satellites," Water Resources Research, vol. 51, no. 4, pp. 2574-2594, 2015.

[30] L. Hu and J. J. Jiao, "Calibration of a large-scale groundwater flow model using GRACE data: a case study in the Qaidam 
Basin, China," Hydrogeology Journal, vol. 23, no. 7, pp. 1305-1317, 2015.

[31] M. Rodell and J. S. Famiglietti, "An analysis of terrestrial water storage variations in Illinois with implications for the Gravity Recovery and Climate Experiment (GRACE)," Water Resources Research, vol. 37, no. 5, pp. 1327-1339, 2001.

[32] J. L. Chen, C. R. Wilson, B. D. Tapley, B. Scanlon, and A. Güntner, "Long-term groundwater storage change in Victoria, Australia from satellite gravity and in situ observations," Global and Planetary Change, vol. 139, pp. 56-65, 2016.

[33] L. Hu and J. J. Jiao, "An innovative method to estimate regionalscale hydraulic diffusivity using GRACE data," Hydrological Sciences Journal, vol. 61, no. 15, pp. 2694-2703, 2016.

[34] S. C. Swenson and J. Wahr, "Post-processing removal of correlated errors in GRACE data," Geophysical Research Letters, vol. 33, no. 8, Article ID L08402, 2006.

[35] S. C. Swenson, D. P. Chambers, and J. Wahr, "Estimating geocenter variations from a combination of GRACE and ocean model output," Journal of Geophysical Research: Solid Earth, vol. 113, no. 8, Article ID B08410, 2008.

[36] J. L. Chen, C. R. Wilson, B. D. Tapley, J. S. Famiglietti, and M. Rodell, "Seasonal global mean sea level change from satellite altimeter, GRACE, and geophysical models," Journal of Geodesy, vol. 79, no. 9, pp. 532-539, 2005.

[37] V. Humphrey, L. Gudmundsson, and S. I. Seneviratne, "Assessing global water storage variability from GRACE: trends, seasonal cycle, subseasonal anomalies and extremes," Surveys in Geophysics, vol. 37, no. 2, pp. 357-395, 2016.

[38] S.-C. Han, J. Sauber, and R. Riva, "Contribution of satellite gravimetry to understanding seismic source processes of the 2011 Tohoku-Oki earthquake," Geophysical Research Letters, vol. 38, no. 24, Article ID L24312, 2011.

[39] S.-C. Han, R. Riva, J. Sauber, and E. Okal, "Source parameter inversion for recent great earthquakes from a decade-long observation of global gravity fields," Journal of Geophysical Research: Solid Earth, vol. 118, no. 3, pp. 1240-1267, 2013.

[40] A. Geruo, J. Wahr, and S. Zhong, "Computations of the viscoelastic response of a 3-D compressible earth to surface loading: an application to glacial isostatic adjustment in Antarctica and Canada," Geophysical Journal International, vol. 192, no. 2, pp. 557-572, 2013.

[41] M. Rodell, P. R. Houser, U. Jambor et al., "The global land data assimilation system," Bulletin of the American Meteorological Society, vol. 85, no. 3, pp. 381-394, 2004.

[42] M. B. Ek, K. E. Mitchell, Y. Lin et al., "Implementation of Noah land surface model advances in the National Centers for Environmental Prediction operational mesoscale Eta model," Journal of Geophysical Research: Atmospheres, vol. 108, no. D22, 2003.

[43] Y. Dai, X. Zeng, R. E. Dickinson et al., "The common land model," Bulletin of the American Meteorological Society, vol. 84, no. 8, pp. 1013-1023, 2003.

[44] D. Long, B. R. Scanlon, L. Longuevergne, A. Y. Sun, D. N. Fernando, and H. Save, "GRACE satellite monitoring of large depletion in water storage in response to the 2011 drought in Texas," Geophysical Research Letters, vol. 40, no. 13, pp. 33953401, 2013.

[45] X. Liang, D. P. Lettenmaier, E. F. Wood, and S. J. Burges, "A simple hydrologically based model of land surface water and energy fluxes for GSMs," Journal of Geophysical Research: Atmospheres, vol. 99, no. D7, pp. 14,415-14,428, 1994.
[46] V. M. Tiwari, J. Wahr, and S. Swenson, "Dwindling groundwater resources in northern India, from satellite gravity observations," Geophysical Research Letters, vol. 36, no. 18, pp. 252-260, 2009.

[47] M. Shamsudduha, R. G. Taylor, and L. Longuevergne, "Monitoring groundwater storage changes in the highly seasonal humid tropics: Validation of GRACE measurements in the Bengal Basin," Water Resources Research, vol. 48, no. 2, Article ID W02508, 2012.

[48] Z. Zhang and L. Li, Groundwater Resources of China, China Cartographic Publishing House, Beijng, China, 2005.

[49] D. Long, L. Longuevergne, and B. R. Scanlon, "Uncertainty in evapotranspiration from land surface modeling, remote sensing, and GRACE satellites," Water Resources Research, vol. 50, no. 2, pp. 1131-1151, 2014.

[50] L. Longuevergne, B. R. Scanlon, and C. R. Wilson, "GRACE hydrological estimates for small basins: evaluating processing approaches on the high plains aquifer, USA," Water Resources Research, vol. 46, no. 11, Article ID W11517, 2010.

[51] J. Wahr, S. Swenson, and I. Velicogna, "Accuracy of GRACE mass estimates," Geophysical Research Letters, vol. 33, no. 6, Article ID L06401, 2006.

[52] H. Bi, J. Ma, W. Zheng, and J. Zeng, "Comparison of soil moisture in GLDAS model simulations and in situ observations over the Tibetan Plateau," Journal of Geophysical Research: Atmospheres, vol. 121, no. 6, pp. 2658-2678, 2016.

[53] H. Kato, M. Rodell, F. Beyrich et al., "Sensitivity of land surface simulations to model physics, land characteristics, and forcings, at four CEOP sites," Journal of the Meteorological Society of Japan-Series II, vol. 85, pp. 187-204, 2007.

[54] K. A. Voss, J. S. Famiglietti, M. Lo, C. De Linage, M. Rodell, and S. C. Swenson, "Groundwater depletion in the Middle East from GRACE with implications for transboundary water management in the Tigris-Euphrates-Western Iran region," Water Resources Research, vol. 49, no. 2, pp. 904-914, 2013.

[55] A. Eicker, M. Schumacher, J. Kusche, P. Döll, and H. M. Schmied, "Calibration/data assimilation approach for integrating GRACE data into the WaterGAP global hydrology model (WGHM) using an ensemble kalman filter: first results," Surveys in Geophysics, vol. 35, no. 6, pp. 1285-1309, 2014.

[56] R. Klees, E. Zapreeva, H. Winsemius, and H. Savenije, "The bias in GRACE estimates of continental water storage variations," Hydrology and Earth System Sciences, vol. 3, pp. 3557-3594, 2006.

[57] Y. N. Pokhrel, Y. Fan, G. Miguez-Macho, P. J.-F. Yeh, and S.-C. Han, "The role of groundwater in the Amazon water cycle: 3 . Influence on terrestrial water storage computations and comparison with GRACE," Journal of Geophysical Research: Atmospheres, vol. 118, no. 8, pp. 3233-3244, 2013. 

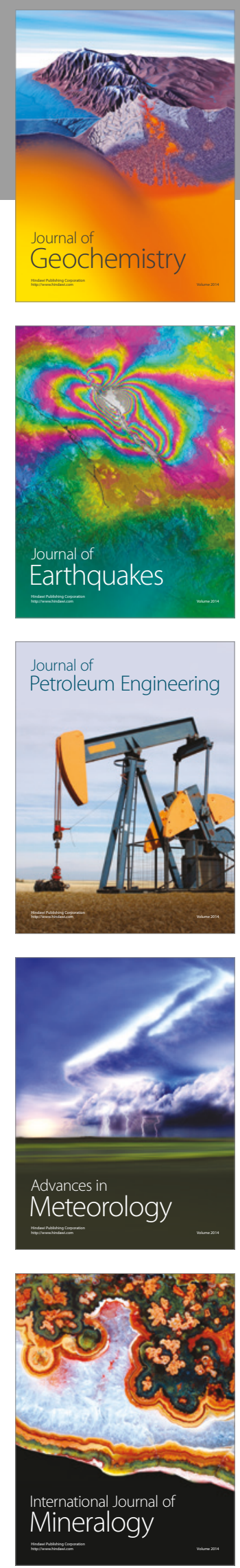
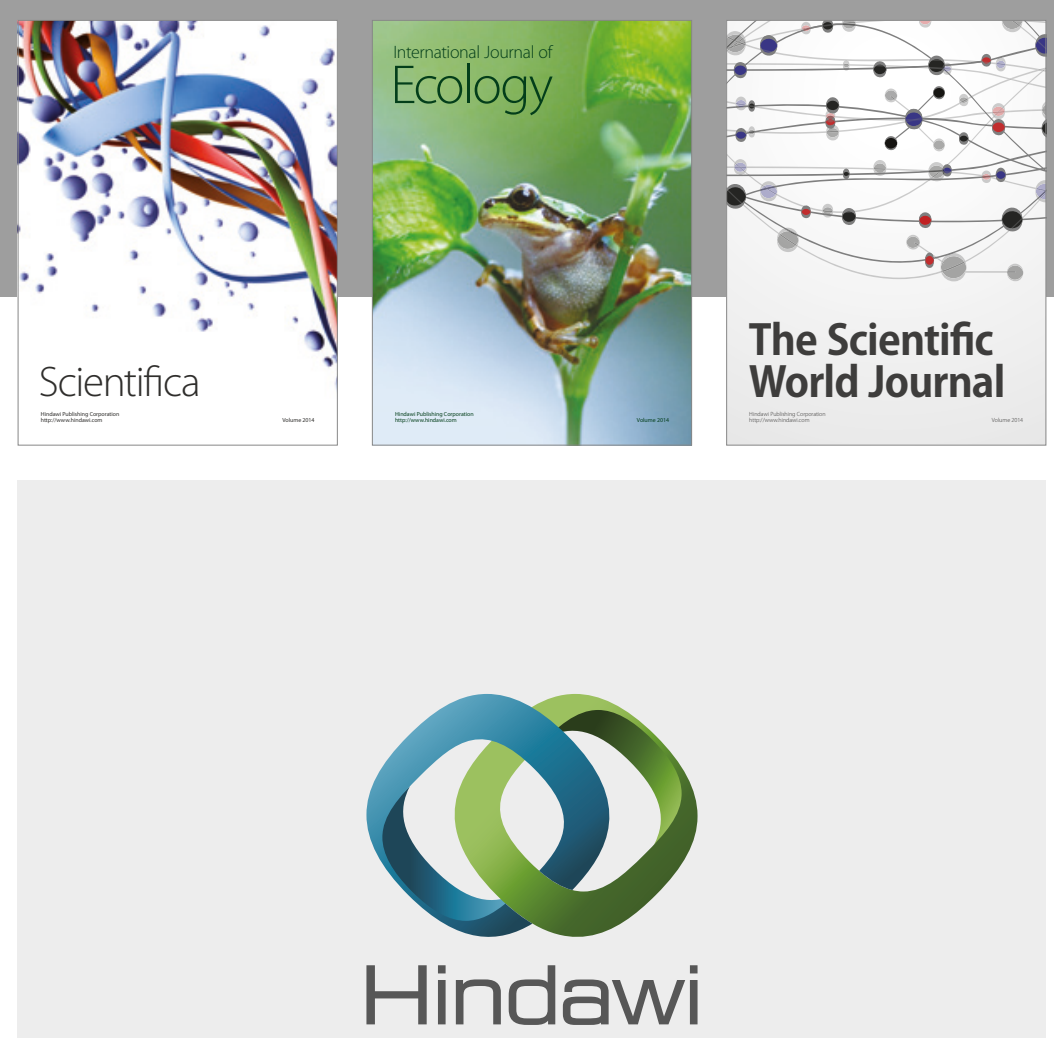

Submit your manuscripts at

https://www.hindawi.com
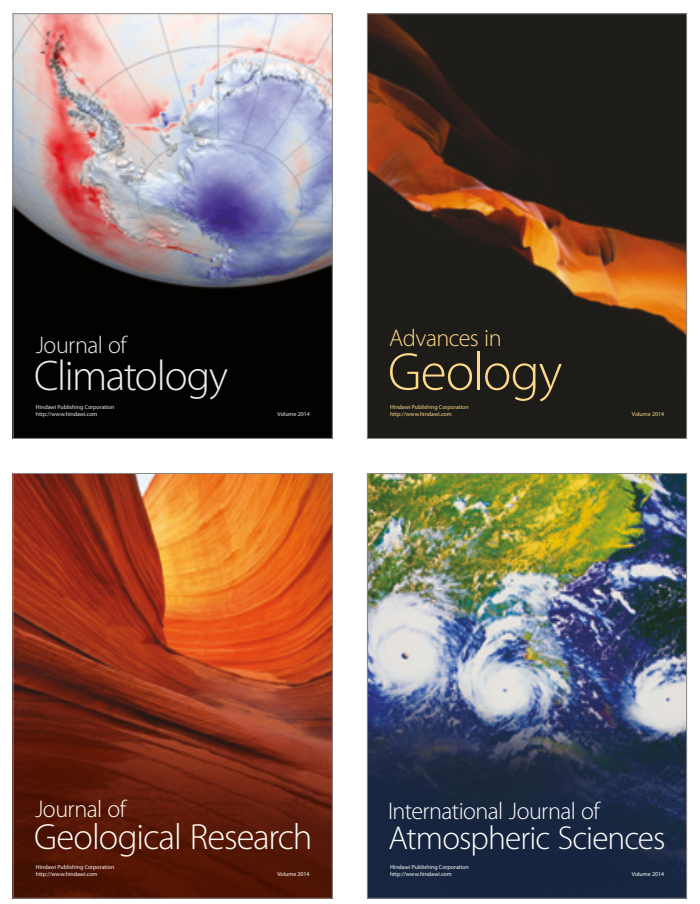

The Scientific

World Journal
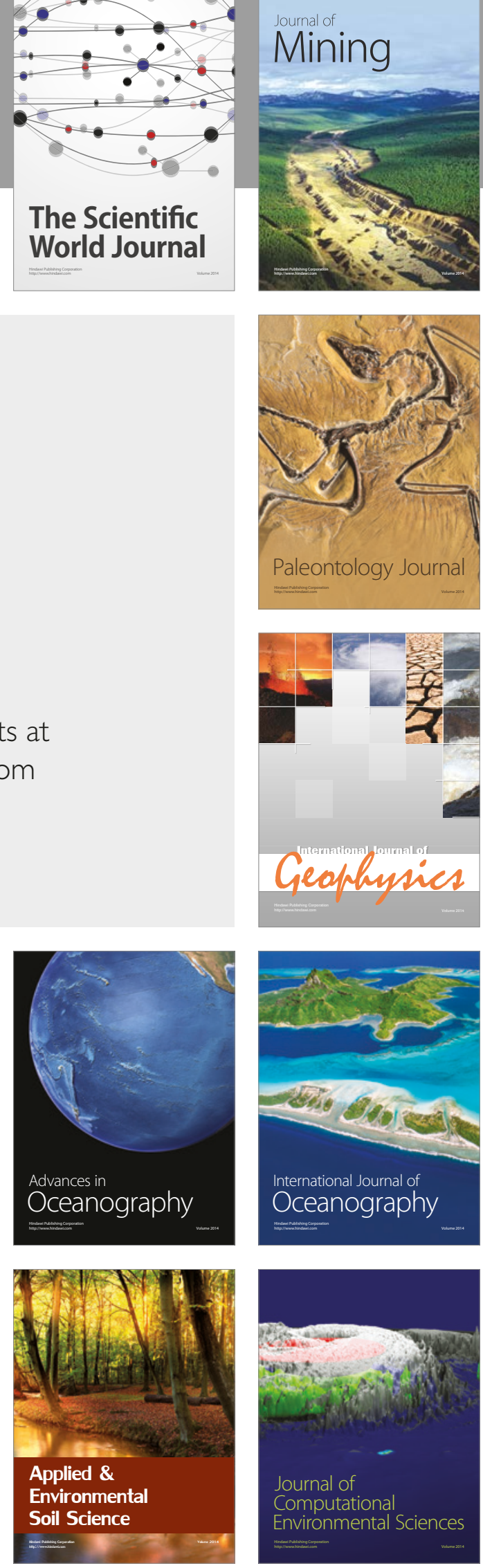